\title{
High Body Mass Index is Associated with Shorter Retention of Tumor Necrosis Factor-Alpha Blocker Treatment in Rheumatoid Arthritis
}

\author{
Ofir Elalouf ${ }^{1,2}$ \\ Merav Lidar ${ }^{2,3}$ \\ Tatiana Reitblat ${ }^{4}$ \\ Devy Zisman ${ }^{5}$ \\ Alexandra Balbir-Gurman ${ }^{6}$ \\ Odelia Hakakian ' \\ Tanya Mashiach ${ }^{7}$ \\ Ronit Almog ${ }^{7}$ \\ Ori Elkayam ${ }^{1,2}$ \\ 'Department of Rheumatology, Tel Aviv \\ Sourasky Medical Center, Tel Aviv, Israel; \\ ${ }^{2}$ Sackler Faculty of Medicine, Tel Aviv \\ University, Tel Aviv, Israel; \\ ${ }^{3}$ Rheumatology Unit, The Zabludowicz \\ Center for Autoimmune Diseases, Sheba \\ Medical Center, Ramat Gan, Israel; \\ ${ }^{4}$ Rheumatology Unit, Barzilai Medical \\ Center, Ashkelon, Israel; ${ }^{5}$ Department of \\ Rheumatology, Carmel Medical Center, \\ Haifa, Israel; ${ }^{6}$ Rheumatology Institute, \\ ${ }^{7}$ Epidemiology and Biostatistics Unit, \\ Rambam Health Care Campus, Haifa, \\ Israel
}

Purpose: To evaluate the association between body mass index (BMI) and tumor necrosis factor $\alpha$ (TNF- $\alpha$ ) blockers retention in patients with rheumatoid arthritis (RA).

Patients and Methods: This prospective cohort study analyzed data about patients with RA who initiated TNF blockers from the Israeli registry of inflammatory diseases from 2011 to 2019. Patients were grouped by BMI: normal (BMI $<24.9 \mathrm{~kg} / \mathrm{m} 2$ ), overweight (BMI $25-$ $29.9 \mathrm{~kg} / \mathrm{m} 2$ ), obese (BMI 30-34.9 kg/m2) and morbid obese (BMI $\geq 35 \mathrm{~kg} / \mathrm{m} 2$ ). Treatment cessation due to inefficacy was defined as an "event" and therapy with a drug above 3 months was defined as a "course." Kaplan-Meier survival curve was used to describe drug survival. Event-free survival was calculated using Cox regression with a hazard ratio and confidence interval of $95 \%$.

Results: The final analysis included 521 RA patients ( $80 \%$ females) treated with etanercept, infliximab, adalimumab or golimumab. Eight hundred and eighteen treatment initiations were included in the final analysis, $334(41 \%)$ in the normal weight group, $261(32 \%)$ in the overweight, $144(17 \%)$ in the obese and $79(10 \%)$ in the morbid obesity group. Three hundred and twenty-six (40\%) treatment initiations were with etanercept, $215(26 \%)$ with adalimumab 197 (24\%) with infliximab, and 80 (10\%) with golimumab. BMI was inversely associated with drug survival. Morbid obese patients were more likely to discontinue treatment compared with normal weight patients HR 2.28 (95\% CI 1.67-3.10, p<0.01). This association remained significant for each drug type (except for golimumab) in a subgroup analysis. Adalimumab switch rate was higher compared to etanercept with HR $=1.51(95 \%$ CI $1.20-1.91, \mathrm{p}<0.01)$, no other significant differences were noted between the other drugs.

Conclusion: Morbid obese RA patients have lower TNF- $\alpha$ blocker retention compared to normal weight patients.

Keywords: TNF alpha, biologics, BMI, obesity, survival

\section{Introduction}

Rheumatoid arthritis is an inflammatory autoimmune disease affecting predominantly the peripheral joints and may lead to destruction and deformity. RA pathogenesis is complex and involves genetic and environmental factors that eventually lead to a breakdown in the immune system balance and to a clinical disease. ${ }^{1}$ Environmental factors contributing to disease evolvement include mainly smoking ${ }^{2}$ and periodontal disease. ${ }^{3}$ Recently, the link between obesity and RA risk and other aspects of the disease including response to therapy is gaining much interest.
Correspondence: Ofir Elalouf

Department of Rheumatology,

Tel Aviv Sourasky Medical Center, 6

Weizmann Street,

Tel Aviv, Israel

Tel +972524262682

Fax +97235422904

Email ofire@tlvmc.gov.il 
The association between obesity and systemic inflammation is suggested by elevated inflammatory markers in obese subjects without any inflammatory disease. ${ }^{4}$ The basal inflammatory state of obese subjects may serve as a contributing factor for the increased risk developing RA. A recent meta-analysis showed 13\% higher risk (RR: 1.13; 95\% CI: 1.01-1.26) developing RA for every $5 \mathrm{~kg} / \mathrm{m}$ increase in BMI. ${ }^{5}$

Several studies demonstrated a decreased response to tumor necrosis factor $\alpha$ (TNF- $\alpha$ ) in obese patients; this correlation was demonstrated with non-weight dependent drugs such as etanercept and adalimumab, ${ }^{6}$ as well as for weight-dependent drugs such as infliximab., ${ }^{7,8}$

On the other hand, few studies reported a presumed positive effect of elevated BMI in RA. Radiographic progression was shown to be decreased in overweight and obese RA patients treated with golimumab, ${ }^{9}$ while a paradoxical protective effect of increased BMI on mortality in RA was reported as well. ${ }^{10} \mathrm{~A}$ recent meta-analysis also reported about a lower radiographic progression in obese RA patients, although obese RA patients had lower quality of life and higher disease activity assessed by DAS-28. ${ }^{11}$

The data regarding the association between BMI and TNF- $\alpha$ blockers retention in RA are sparse, and to our knowledge only two studies addressed this important matter. A reduced retention of second line biologic (including TNF- $\alpha$ blockers, rituximab, tocilizumab and abatacept) after a failure of a first line TNF- $\alpha$ blockers was reported to be lower in obese RA patients, while first-line TNF- $\alpha$ blocker showed the same trend although insignificant. ${ }^{12}$ Surprisingly, a recent study based on Veterans Affairs administrative databases reported an opposite correlation with a better drug survival (TNF- $\alpha$ blockers, MTX and hydroxychloroquine) in obese (BMI 25-30) compared to low $(\mathrm{BMI}<20 \mathrm{~kg} / \mathrm{m} 2)$ and normal BMI $(25-30 \mathrm{~kg} / \mathrm{m} 2)$. No difference in anti TNF- $\alpha$ blockers retention was demonstrated between the morbid obese group $(\mathrm{BMI}>35)$ to the other groups. ${ }^{13}$ Given the insufficient and conflicting data regarding the association of BMI and multiple TNF- $\alpha$ blocker retention, we tried to address this question thru prospectively collected data of the Israeli registry of inflammatory diseases.

\section{Study objectives}

The primary objective of this study was to evaluate the association between BMI and TNF- $\alpha$ blocker retention in patients with RA. The secondary endpoints were as follows: 1) to compare whether there was a difference in drug retention between the different TNF- $\alpha$ blockers in relation to the BMI, and 2) to test the effect of additional parameters, such as line of treatment, age, gender, smoking, disease activity, sero-positivity (rheumatoid factor or anti$\mathrm{CCP}$ ) and methotrexate (MTX) usage on drug retention.

\section{Patients and Methods}

This is a prospective cohort study that analyzed data collected from six medical centers from the Israeli registry of inflammatory diseases from 2011 to 2019. The study participants fulfill ACR criteria for $\mathrm{RA}^{14}$ and signed an informed consent form. The study complies with the Declaration of Helsinki, and was approved by the locally appointed ethics committee at Tel Aviv Sourasky (Ichilov) medical center number 0332-10. Patients with active RA despite synthetic disease modifying anti-rheumatic drug (sDMARD) therapy that were treated with anti-TNF- $\alpha$ for at least 3 months during 2011-2019 were included in this study. The biologic drug was chosen by the treating rheumatologist according to his medical decision. Dosage of the drugs was based on recommendations in the marketing registrations. The Israeli health system is public and all citizens are entitled to fully funded medical therapies including biological treatments, without any specific drug restriction.

Patients' data are collected at the enrollment (baseline) and every 6 months thereafter. The prospectively collected data included patient demographics, BMI, and medical history that included disease duration, RF (rheumatic factor), ACPA (anti-citrullinated peptide antibody) drug therapy including type and dosage of sDMARD (MTX was the only sDMARD that was analyzed given the very low numbers of patients treated with other sDMARDS concomitantly with biologics). ESR (erythrocyte sedimentation rate), CRP (C-reactive protein) and disease activity scores including ESR-DAS-28 and CRP-DAS28. The BMI was calculated by weight in kilograms divided by square height at baseline. The patients were grouped according to the WHO criteria for the BMI as being normal $(<24.9 \mathrm{~kg} / \mathrm{m} 2)$, overweight (25-29.9 kg/m2), obese ( $\geq 30-34.9 \mathrm{~kg} / \mathrm{m} 2)$, and morbid obese $(\geq 35 \mathrm{~kg} / \mathrm{m} 2)$. The treatment duration was measured from the initiation of infliximab, adalimumab, etanercept or golimumab (cetrolizumab-pegol was not included due to very low numbers of patients), and that period could be as short as 3 months (patients with shorter treatment period was excluded due to inability to refer the cessation to inefficacy) and reach up to a maximum of 5 years (analysis was truncated at maximal duration of 5 years of treatment). More 
than one drug course per patient was possible if a patient was switched from one TNF- $\alpha$ blocker to another. The treatment retention was defined as the number of patients remaining on any treatment regimen at a predefined timepoint. The reasons for discontinuation included inefficacy, side effects or any other reason.

\section{Statistical Analysis}

The BMI was defined as an independent variable. Length of treatment with TNF- $\alpha$ blocker was defined as a dependent variable. The Chi-square test was used to determine differences between patients based on their disease characteristics. The correlation of BMI and drug survival was evaluated by two methods. First Kaplan-Meier curves were used to describe drug cessation due to all reasons including inefficacy, adverse events, pregnancy, etc. Second, the association between BMI and cessation solely due to inefficacy was calculated using Cox regression with a Hazard Ratio (HR) and Confidence Interval (CI) of 95\%. For comparisons between different drug retention, Cox regression with HR and CI of $95 \%$ was used as well. Statistical significance was set at $\mathrm{P}<0.05$. The analysis was truncated at 5 years for each patient, assuming that limiting this period is the most accurate assessment of drug survival by the avoidance of outliers. The statistical software was SPSS version 20 for Windows (IBM Corp., Armonk, NY).

\section{Results}

The demographic and clinical characteristics of the study participants are presented in Table 1 . The registry included

Table I Demographic and Clinical Characteristics of the Patients Stratified by Courses

\begin{tabular}{|c|c|c|c|c|c|c|}
\hline Variables & Total & Normal BMI & Overweight & Obese & Morbid Obese & $P$ value \\
\hline Courses, n (\%) & $818(100)$ & $334(4 I)$ & $26 I(32)$ & 144(18) & 79(9) & \\
\hline Patients, n (\%) & $521(100)$ & $210(40)$ & $168(32)$ & $94(18)$ & $49(10)$ & $<0.01$ \\
\hline Mean age at diagnosis [years (SD)] & $42(16)$ & $38(17)$ & $46(16)$ & $46(16)$ & $42(15)$ & $<0.01$ \\
\hline Mean age at episode [years (SD)] & $52(16)$ & $5 I(16)$ & $56(13)$ & $58(13)$ & $54(12)$ & $<0.01$ \\
\hline Male gender [n (\%)] & $102(20)$ & $38(18)$ & $47(28)$ & $9(10)$ & $8(16)$ & $<0.01$ \\
\hline Disease duration [years (SD)] & $13(13)$ & $13(13)$ & $\mathrm{II}(\mathrm{II})$ & $12(\mid I)$ & $13(12)$ & \\
\hline \multicolumn{7}{|l|}{ Smoking, n (\%) } \\
\hline Never & $400(49)$ & $160(61)$ & $130(65)$ & $69(59)$ & $4 I(73)$ & 0.36 \\
\hline Past & $123(15)$ & $48(19)$ & $39(19)$ & $25(22)$ & $\mathrm{II}(20)$ & \\
\hline Current & $112(14)$ & $53(20)$ & $33(16)$ & $22(19)$ & $4(7)$ & \\
\hline \multicolumn{7}{|l|}{ Drug, n (\%) } \\
\hline Etanercept & $287(34)$ & $122(38)$ & $96(37)$ & $4 I(28)$ & $28(35)$ & $<0.01$ \\
\hline Infliximab & 284(34) & $128(38)$ & $8 I(3 I)$ & $53(37)$ & $22(28)$ & \\
\hline Adalimumab & $149(17)$ & $52(16)$ & $54(2 I)$ & $32(22)$ & $\mathrm{II}(14)$ & \\
\hline Golimumab & $44(5)$ & $16(5)$ & $20(8)$ & $7(5)$ & $\mathrm{I}(\mathrm{I})$ & \\
\hline \multicolumn{7}{|l|}{ Biologic line } \\
\hline First & $487(60)$ & $200(60)$ & $160(61)$ & $87(60)$ & $40(51)$ & 0.39 \\
\hline Second + & $33 I(40)$ & I34(40) & I0I (39) & $57(40)$ & $39(49)$ & \\
\hline \multicolumn{7}{|l|}{ MTX, n (\%) } \\
\hline No & $162(20)$ & $75(22)$ & $44(17)$ & $28(19)$ & $15(19)$ & 0.4 \\
\hline Yes & $656(80)$ & $259(78)$ & $217(83)$ & $116(81)$ & $64(81)$ & \\
\hline \multicolumn{7}{|l|}{ Cessation reason, n (\%) } \\
\hline Inefficacy & $46 I(56)$ & $183(55)$ & $|4|(55)$ & $76(53)$ & $6 \mathrm{I}(77)$ & 0.02 \\
\hline Adverse events & $12 \mid(15)$ & $50(15)$ & $35(13)$ & $26(18)$ & $10(12)$ & \\
\hline Other reasons & $82(10)$ & $36(11)$ & $29(11)$ & $15(10)$ & $2(3)$ & \\
\hline No change & I54(19) & $65(19)$ & $56(2 I)$ & $27(19)$ & $6(8)$ & \\
\hline
\end{tabular}

Abbreviation: BMI, body mass index; RA, rheumatoid arthritis; MTX, methotrexate. 
521 patients (419 females 80\%) who were treated with etanercept, infliximab, adalimumab or golimumab. A total number of 818 treatments courses were included in the final analysis, 326 (39\%) with etanercept, 215 (26\%) with adalimumab, 197 (24\%) with infliximab, and 80 (9.7\%) with golimumab. There were $334(40.8 \%)$ drug courses in the normal BMI group, 261 (31.9\%) in the overweight group, 144 (17.6) in the obese group, and $79(9.6 \%)$ in the morbid obese group. The drug was discontinued due to inefficacy in $407(49.8 \%)$ times, with an overall retention rate of $71 \%$, $54 \%, 46 \%, 41 \%$ and $38 \%$ after the first, second, third, fourth and fifth years, respectively. There were 109 additional treatment cessations due to adverse side effects (most commonly allergic, dermatologic and infectious), and the rate of adverse events did not differ between the BMI groups (data not shown). MTX was used in 656 (80\%) courses, while 162 (20\%) episodes occurred in patients not receiving MTX. Drug retention did not differ between MTX users and nonusers with $\mathrm{HR}=1.09$ (95\% CI 0.85-1.4; $\mathrm{P}=0.51)$.

\section{Primary Endpoint: The Effect of the BMI on Drug Retention}

Table 1 shows the patients' characteristics stratified by treatment episodes. A total of 818 courses were included in the final analysis, of which 334 (41\%) occurred in the normal BMI group, 261 (32\%) in the overweight group, 144 (18\%) in the obese group and $79(9 \%)$ in the morbid obese group.

For the whole group, a significant correlation between an increased BMI especially morbid obese patients and decreased retention was demonstrated (Figure 1). Patients who were morbidly obese were more likely to discontinue treatment compared to those with normal BMI (HR 2.26; 95\% CI 1.36-3.78) A similar trend was seen in the obese and overweight patients compared to patients with a normal BMI (HR 1.15; 95\% CI 0.72-1.81, $\mathrm{P}=0.24$; HR-1.27 95\% CI 0.87-1.86, respectively); however, it did not reach statistical significance.

The effect of the BMI on the duration of drug retention is shown in Table 2. Patients with a normal BMI had 1-, 3and 5 -year retention rates of $78 \%, 52 \%$ and $43 \%$, respectively, overweight patients had rates of $71 \%$ and $45 \%$ and $39 \%$, obese patients' retention rates was $64 \%, 51 \%$ and $38 \%$, and morbid obese retention was lowest with $51 \%$, $20 \%$ and $16 \%$, respectively.

\section{Drug Survival by Specific TNF- $\alpha$ Blocker}

Etanercept showed the highest drug retention rate followed by infliximab, while adalimumab had the lowest drug

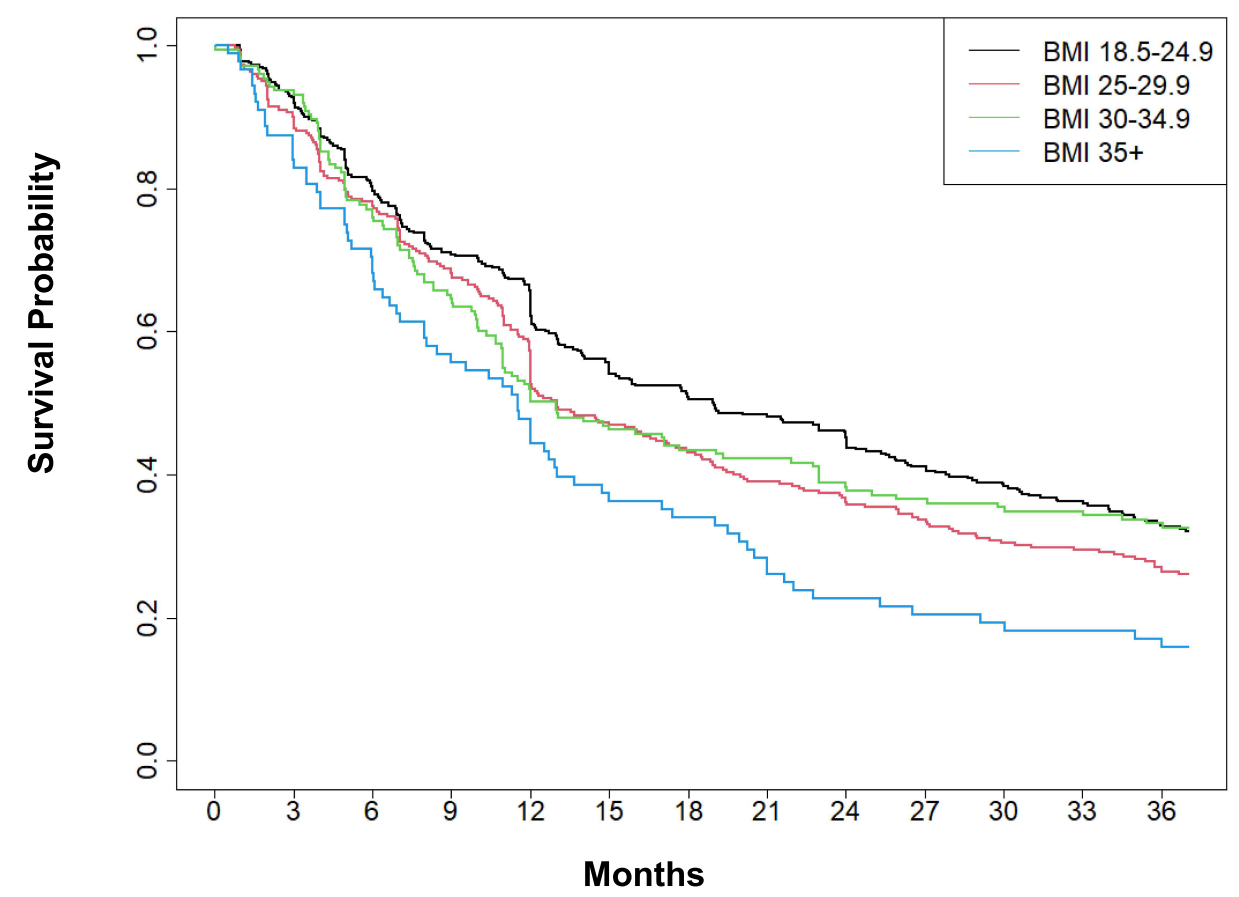

Figure I All drugs retention and correlation to BMI. 
Table 2 Drug Retention According to BMI and Other Variables

\begin{tabular}{|c|c|c|c|c|c|c|c|c|}
\hline Variable & Episodes & Events (\%) & HR & $95 \% \mathrm{Cl}$ & $P$-value & I Year (\%) & 3 Year (\%) & 5 Year (\%) \\
\hline Total & 818 & $407(50)$ & & & & 71 & 46 & 38 \\
\hline Etanercept & 326 & I54(47) & 1.00 & & & 74 & 52 & 43 \\
\hline Infliximab & 197 & $94(48)$ & I.II & $0.86-1.44$ & 0.42 & 75 & 45 & 37 \\
\hline Adalimumab & 215 & 127(59) & $1.5 \mathrm{I}$ & $1.20-1.9 \mid$ & $<0.01$ & 61 & 38 & 29 \\
\hline Golimumab & 80 & $32(30)$ & 1.12 & $0.76-1.64$ & 0.56 & 72 & 48 & 40 \\
\hline \multicolumn{9}{|l|}{ BMI } \\
\hline Normal & 134 & $56(42)$ & 1.00 & & & 80 & 58 & 49 \\
\hline Overweight & 104 & $5 I(49)$ & 1.27 & $0.87-1.86$ & 0.21 & 73 & 48 & 43 \\
\hline Obese & 59 & $27(46)$ & 1.15 & $0.72-|.8|$ & 0.56 & 71 & 58 & 42 \\
\hline Morbid Obese & 29 & $20(69)$ & 2.26 & $1.36-3.78$ & $<0.01$ & 53 & 26 & 21 \\
\hline \multicolumn{9}{|l|}{ Normal BMI } \\
\hline Etanercept & 134 & $56(42)$ & 1.00 & & & 80 & 58 & 49 \\
\hline Infliximab & 79 & $34(43)$ & 0.97 & $0.63-1.48$ & 0.87 & 86 & 58 & 47 \\
\hline Adalimumab & 89 & $47(53)$ & 1.58 & $1.07-2.33$ & 0.02 & 69 & 40 & 35 \\
\hline Golimumab & 32 & $15(47)$ & 1.83 & $1.03-3.26$ & 0.04 & 73 & 31 & NA \\
\hline \multicolumn{9}{|l|}{ Overweight } \\
\hline Etanercept & 104 & $5 I(49)$ & 1.00 & & 0.148 & $73 \%$ & $58 \%$ & $48 \%$ \\
\hline Infliximab & 58 & $26(44.8)$ & 1.16 & $0.72-1.86$ & 0.549 & $77 \%$ & $40 \%$ & $36 \%$ \\
\hline Adalimumab & 69 & $43(62.3)$ & 1.43 & $0.95-2.15$ & 0.085 & $62 \%$ & $44 \%$ & $38 \%$ \\
\hline Golimumab & 30 & $9(39)$ & 0.69 & $0.34-1.4$ & 0.301 & $75 \%$ & $64 \%$ & $64 \%$ \\
\hline \multicolumn{9}{|l|}{ Obese } \\
\hline Etanercept & 59 & $27(45.8)$ & 1.00 & & 0.620 & $71 \%$ & $61 \%$ & $58 \%$ \\
\hline Infliximab & 38 & $19(50)$ & 1.39 & $0.77-2.5$ & 0.272 & $61 \%$ & $54 \%$ & $43 \%$ \\
\hline Adalimumab & 36 & $19(52.8)$ & 1.41 & $0.78-2.53$ & 0.256 & $53 \%$ & $50 \%$ & $45 \%$ \\
\hline Golimumab & 11 & $5(45.5)$ & 1.17 & $0.45-3.03$ & 0.754 & $71 \%$ & $53 \%$ & $35 \%$ \\
\hline \multicolumn{9}{|l|}{ Morbid obese } \\
\hline Etanercept & 29 & $20(69)$ & 1.00 & & & 53 & 26 & 21 \\
\hline Infliximab & 22 & $15(68)$ & 1.04 & $0.53-2.03$ & 0.91 & 56 & 22 & NA \\
\hline Adalimumab & 21 & $18(86)$ & 1.66 & $0.88-3.15$ & 0.12 & 40 & 12 & NA \\
\hline Golimumab & 7 & $3(43)$ & 1.14 & $0.33-3.91$ & 0.83 & 60 & NA & NA \\
\hline \multicolumn{9}{|c|}{ Treatment line } \\
\hline First & 487 & $224(46)$ & 1.00 & & & 76 & 50 & 40 \\
\hline Second+ & 331 & $183(55)$ & 1.35 & $1.11-1.64$ & $<0.01$ & 63 & 40 & 34 \\
\hline \multicolumn{9}{|l|}{ MTX } \\
\hline No & 162 & $73(45)$ & 1.00 & & & 67 & 49 & 45 \\
\hline Yes & 656 & $(334(5 I)$ & 1.09 & $0.85-1.40$ & 0.51 & 72 & 46 & 36 \\
\hline \multicolumn{9}{|l|}{ Smoking } \\
\hline Never & 400 & 197(49) & 1.00 & & & 73 & 46 & 38 \\
\hline Past & 123 & $54(40)$ & 0.89 & $0.66-1.20$ & 0.42 & 69 & 51 & 46 \\
\hline Current & 112 & $49(44)$ & 0.92 & $0.67-1.26$ & 0.60 & 67 & 50 & 44 \\
\hline
\end{tabular}

Abbreviations: Event, drug cessation due to inefficacy; HR, hazard ratio; $\mathrm{Cl}$, confidence interval; BMI, body mass index; MTX, methotrexate. 
retention rate (Figure 2). The median length of retention was 42.5 months for etanercept, 33.4 months for infliximab and 24.4 months for adalimumab.

The 1-year retention rate was $74 \%$ for etanercept, $75 \%$ for infliximab, and $61 \%$ for adalimumab, and $72 \%$ for golimumab, while the respective 5-year retention rate was $43 \%, 37 \%, 29 \%$ and $40 \%$. There was a significant difference in retention between etanercept and adalimu$\mathrm{mab}$ in favor of the former (HR 1.51; 95\% CI 1.20-1.91, $\mathrm{P}<0.01)$. Etanercept had the best drug retention trend in the different BMI groups as well.

The trend for lower drug retention in the morbid obese group was demonstrated in all four TNF- $\alpha$ blockers. This trend was statistically significant for all drugs, except for golimumab. Morbid obese patients treated with etanercept had a higher rate of drug switching compared to patients with normal BMIs (HR 2.26; 95\% CI 1.36-3.78, P < 0.01). Infliximab-treated morbid obese patients showed a similar trend (HR 2.57; 95\% CI 1.39-4.74, $\mathrm{P}<0.01$ ), and a comparison between the obese group and the normal BMI group yielded an HR of 1.75 (95\% CI 1.00-3.08; $\mathrm{P}=0.05)$. The adalimumab HR was 2.42 (95\% CI $1.40-$ $4.18, \mathrm{P}<0.01)$, again reflecting a higher rate of drug retention in the patients with a normal BMI compared to the morbid obese group.

\section{Secondary endpoints}

Figure 3 shows that second-line treatment and above was related to lower drug retention compared to first-line treatment (HR 1.35; 95\% CI 1.11-1.64, P $<0.01$ ). When looking into first-line treatment courses, lower drug retention was noted also for the obese group (and not only the morbid obese group as was shown to all lines of treatment) compared to the normal weight group. Higher disease activity (represented by DAS28) was positively correlated with a higher rate of switching drugs (data not shown). The use of MTX, gender, smoking status and seropositivity did not seem to affect the rate of drug retention in RA patients.

\section{Discussion}

The correlation between obesity and the response to TNF$\alpha$ blockers is inconclusive, and data on the rate of retention of those drugs are sparse. We evaluated the effect of the $\mathrm{BMI}$ on the rate of retention of four TNF- $\alpha$ blockers in 521 RA patients and total of 818 treatment courses who were

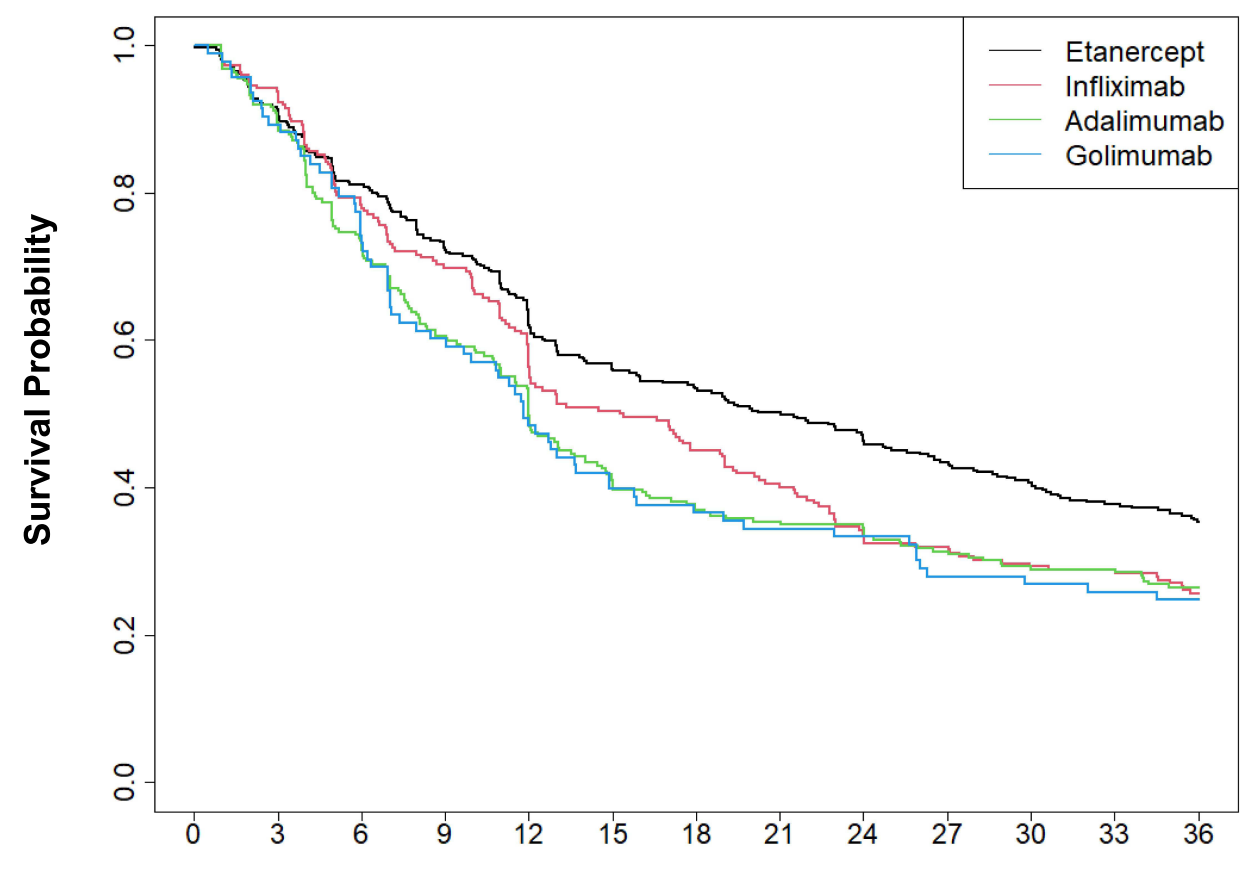

Months

Figure 2 Specific drug retention in all BMI groups. 


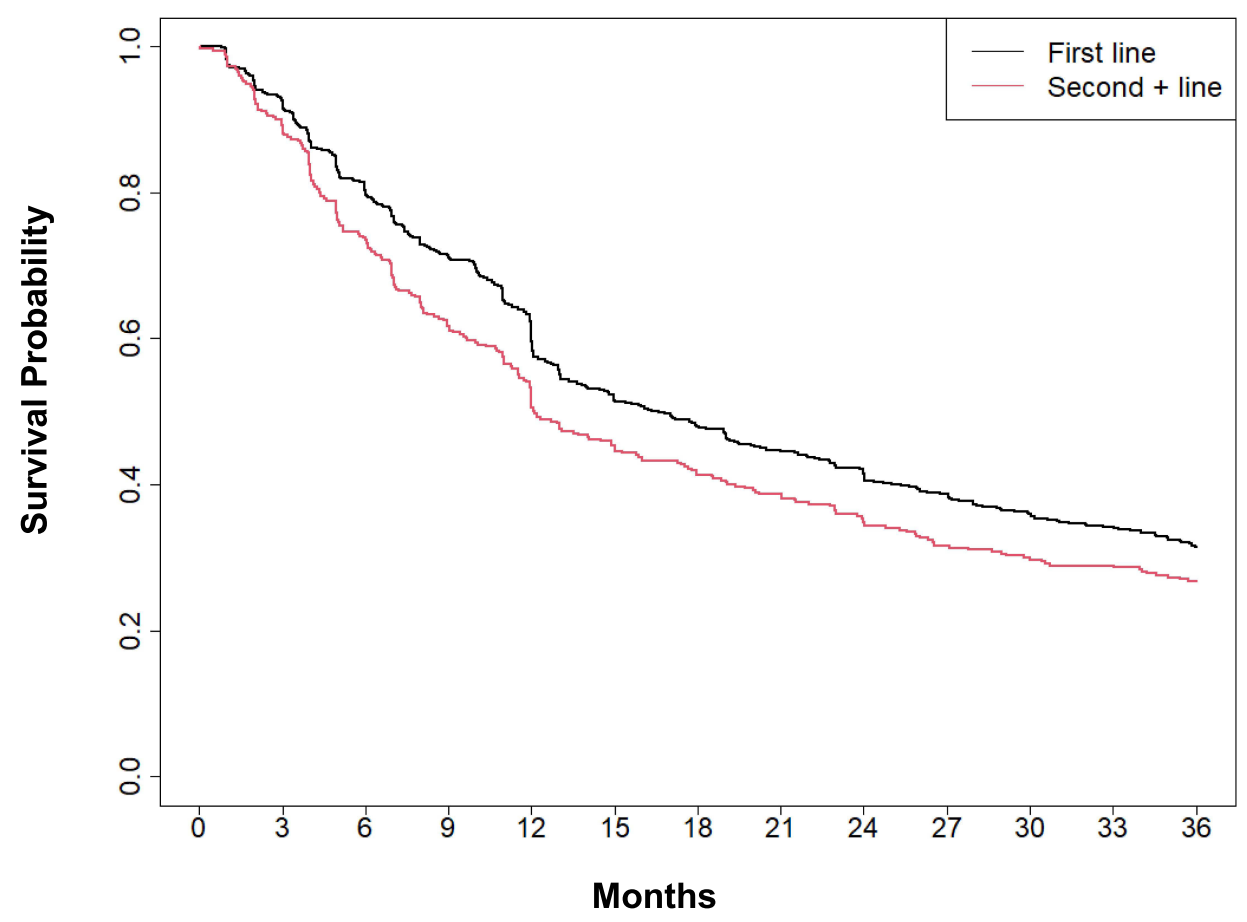

Figure 3 Drug retention by line of treatment.

included in the Israeli registry of inflammatory diseases. Decreased drug retention was significantly associated with morbid obese patients in this population, and it was lowest for adalimumab compared to etanercept.

To the best of our knowledge, this is the first study to reveal the negative impact of a high BMI on drug retention in RA patients treated with a variety of TNF- $\alpha$ blockers. Previous studies mostly sought an association between the BMI and therapeutic response, and their findings have supported this association. Gremese et al evaluated the correlation between the BMI and response to treatment with TNF- $\alpha$ blockers in RA, and their results showed that obesity is a risk factor for a poor remission rate in long-standing RA. ${ }^{6}$ It could be expected that the response to a weight-dependent drug dose would be better than that to a fixed dose in obese patients, but this was not demonstrated in our current study. This finding supports the notion that adipose tissue may be involved in the pathophysiology of RA and that it could have implications for other immune-mediated inflammatory conditions that are treated with TNF antagonists. ${ }^{7}$ The importance of fat as an endocrine tissue and its immunological effect by the secretion of pro-inflammatory cytokines, such as tumor necrosis factor-alpha (TNF- $\alpha)$, and the overexpression of specific adipokines secreted by visceral fat are well known. ${ }^{15}$ Fat functions as a major intermediate of inflammation and immunity, and it plays a major role in the whole-body metabolism of lipids and glucose and, consequently, in the pathogenesis of insulin tolerance. ${ }^{16-18} \mathrm{TNF}-\alpha$ is a proinflammatory cytokine secreted by a number of cells, including lymphocytes, macrophages and keratinocytes. The cellular response to TNF- $\alpha$ is mediated by two receptors, TNF-receptor 1 and TNF receptor 2. ${ }^{19-22}$ Hotamisligil et al reported an increase in mRNA levels of TNF-receptor 2 in fat tissue as well as an increase of soluble TNF-receptor in the blood of obese women. ${ }^{23}$ Fernandez-Real et al showed a positive correlation between plasma soluble TNF-receptor 2 levels and body mass index (BMI). ${ }^{24}$ Tanaka et al investigated the function of lymphocyte subsets in obese patients and showed that subsets of $\mathrm{T}$ cell populations and their function may be reduced in obese individuals and that this may be partly related to the elevated production of TNF- $\alpha .^{25}$

Very few studies have looked into the effect of a high BMI on drug retention in the setting of immune diseases. Iannone et $\mathrm{al}^{12}$ reported decreased retention rates of TNF$\alpha$ blockers in obese RA patients who were receiving a second-line biological drug (eg, TNF- $\alpha$ blocker, abatacept, tocilizumab and rituximab). A same trend was observed for a first-line TNF- $\alpha$ blocker, but the difference 
was not statistically significant. A lower drug retention rate correlated with an increased BMI in 97 patients receiving a non-TNF agent for the second-line treatment, while obese patients had a $43.5 \%$ retention rate vs a rate of $80 \%$ in the normal weight population $(\mathrm{P}=0.04)$.

Interestingly, the findings of the current work revealed that etanercept and infliximab had better rates of drug retention than adalimumab. This difference might be related to the basic biologic features of the drug itself. Another possible explanation is the delayed chronological marketing of adalimumab compared to infliximab and etanercept. When only two biologic options were available, the threshold for a drug switch might have been much higher compared to the current availability of many therapeutic options.

Our study supports the finding of a negative effect of the BMI on the TNF- $\alpha$ blocker retention rate, and adds to the sparse evidence that morbid obese RA patients have lower rates of TNF- $\alpha$ blocker retention than non-obese patients. The reasons for this correlation remain unclear. However, the finding that the BMI affects both weightdependent (infliximab) and weight-independent (adalimumab, etanercept and golimumab for the majority of patients) drugs supports the theory that body fat itself has a pro-inflammatory function, and it is not just a matter of higher volume of distribution. The relation of adipose tissue and its pro-inflammatory function was described both in rheumatological disease as well as in healthy controls. ${ }^{15-18,26}$ Our results indirectly indicate a potential benefit of weight reduction in inflammatory diseases, and should serve to increase the awareness of physicians and patients of this modifiable prognostic factor.

One of the limitations of this work is that it is a retrospective analysis and has the drawbacks inherent to such a study design. The BMI data were available for only about two-thirds of the patients in the registry. Data on comorbidities were not precise and therefore not included in the analysis. Diseases, such as osteoarthritis, fibromyalgia and depression may have influenced the decision to switch drugs and thereby cause a bias. Another fundamental issue is that we are using the BMI as a surrogate marker for obesity. The BMI is not an optimal reflection of obesity, and there are individuals with a normal BMI who have central obesity and elevated fat percentages, as well as people with elevated BMIs and normal fat distribution.

\section{Conclusion}

Our study findings demonstrate that morbid obesity reduces the retention rate of infliximab, adalimumab, golimumab and etanercept in patients with RA. Further studies looking into more accurate measures of obesity, such as fat percentage, and their effect on drug retention are warranted.

\section{Disclosure}

Professor Ori Elkayam reports grants, personal fees from AbbVie, Novartis, Pfizer, Lilly, BI, Roche, Gilead, outside the submitted work. All authors have nothing further to disclose.

\section{References}

1. Lee DM, Weinblatt ME. Rheumatoid arthritis. Lancet. 2001;358 (9285):903-911. doi:10.1016/s0140-6736(01)06075-5

2. Lundstrom E, Kallberg H, Alfredsson L, Klareskog L, Padyukov L. Gene-environment interaction between the DRB1 shared epitope and smoking in the risk of anti-citrullinated protein antibody-positive rheumatoid arthritis: all alleles are important. Arthritis Rheum. 2009;60(6):1597-1603. doi:10.1002/art.24572

3. Koziel J, Mydel P, Potempa J. The link between periodontal disease and rheumatoid arthritis: an updated review. Curr Rheumatol Rep. 2014;16(3):408. doi:10.1007/s11926-014-0408-9

4. Panagiotakos DB, Pitsavos C, Yannakoulia M, Chrysohoou C, Stefanadis C. The implication of obesity and central fat on markers of chronic inflammation: the ATTICA study. Atherosclerosis. 2005;183(2):308-315. doi:10.1016/j.atherosclerosis.2005.03.010

5. Feng J, Chen Q, Yu F, et al. Body mass index and risk of rheumatoid arthritis: a meta-analysis of observational studies. Medicine. 2016;95 (8):e2859. doi:10.1097/MD.0000000000002859

6. Gremese E, Carletto A, Padovan M, et al. Obesity and reduction of the response rate to anti-tumor necrosis factor alpha in rheumatoid arthritis: an approach to a personalized medicine. Arthritis Care Res. 2013;65(1):94-100. doi:10.1002/acr.21768

7. Klaasen R, Wijbrandts CA, Gerlag DM, Tak PP. Body mass index and clinical response to infliximab in rheumatoid arthritis. Arthritis Rheum. 2011;63(2):359-364. doi:10.1002/art.30136

8. Ottaviani S, Gardette A, Tubach F, et al. Body mass index and response to infliximab in rheumatoid arthritis. Clin Exp Rheumatol. 2015;33(4):478-483.

9. Baker JF, Ostergaard M, George M, et al. Greater body mass independently predicts less radiographic progression on X-ray and MRI over 1-2 years. Ann Rheum Dis. 2014;73(11):1923-1928. doi:10.1136/annrheumdis-2014-205544

10. Escalante A, Haas RW, Del Rincon I. Paradoxical effect of body mass index on survival in rheumatoid arthritis: role of comorbidity and systemic inflammation. Arch Intern Med. 2005;165(14):1624-1629. doi:10.1001/archinte.165.14.1624

11. Vidal C, Barnetche T, Morel J, Combe B, Daien C. Association of body mass index categories with disease activity and radiographic joint damage in rheumatoid arthritis: a systematic review and metaanalysis. J Rheumatol. 2015;42(12):2261-2269. doi:10.3899/ jrheum. 150224

12. Iannone F, Fanizzi R, Notarnicola A, Scioscia C, Anelli MG, Lapadula G. Obesity reduces the drug survival of second line biological drugs following a first TNF- $\alpha$ inhibitor in rheumatoid arthritis patients. Joint Bone Spine. 2015;82(3):187-191. doi:10.1016/j. jbspin.2014.12.006 
13. McCulley CB, Barton JL, Cannon GW, et al. Body mass index and persistence of conventional DMARDs and TNF inhibitors in rheumatoid arthritis. Clin Exp Rheumatol. 2019;37(3):422-428.

14. Aletaha D, Neogi T, Silman AJ, et al. 2010 Rheumatoid arthritis classification criteria: an American College of Rheumatology/ European League Against Rheumatism collaborative initiative. Arthritis Rheum. 2010;62(9):2569-2581. doi:10.1002/art.27584

15. Tilg H, Moschen AR. Adipocytokines: mediators linking adipose tissue, inflammation and immunity. Nat Rev Immunol. 2006;6 (10):772-783. doi:10.1038/nri1937

16. Grunfeld C, Feingold KR. The metabolic effects of tumor necrosis factor and other cytokines. Biotherapy. 1991;3(2):143-158. doi:10.1007/BF02172087

17. Schottelius AJ, Moldawer LL, Dinarello CA, Asadullah K, Sterry W, Edwards CK Biology of tumor necrosis factor-alpha- implications for psoriasis. Exp Dermatol. 2004;13(4):193-222. doi:10.1111/j.09066705.2004.00205.x

18. Yamakawa T, Tanaka S, Tamura K, et al. Wistar fatty rat is obese and spontaneously hypertensive. Hypertension. 1995;25(1):146-150. doi:10.1161/01.HYP.25.1.146

19. Engelmann H, Novick D, Wallach D. Two tumor necrosis factor-binding proteins purified from human urine. Evidence for immunological cross-reactivity with cell surface tumor necrosis factor receptors. J Biol Chem. 1990;265(3):1531-1536. doi:10.1016/ S0021-9258(19)40049-5

20. Loetscher H, Pan YC, Lahm HW, et al. Molecular cloning and expression of the human $55 \mathrm{kd}$ tumor necrosis factor receptor. Cell. 1990;61(2):351-359. doi:10.1016/0092-8674(90)90815-V
21. Seckinger P, Isaaz S, Dayer JM. Purification and biologic characterization of a specific tumor necrosis factor alpha inhibitor. $J$ Biol Chem. 1989;264(20):11966-11973. doi:10.1016/S0021-9258(18) 80161-2

22. Smith CA, Davis T, Anderson D, et al. A receptor for tumor necrosis factor defines an unusual family of cellular and viral proteins. Science. 1990;248(4958):1019-1023. doi:10.1126/science.2160731

23. Hotamisligil GS, Arner P, Atkinson RL, Spiegelman BM. Differential regulation of the $\mathrm{p} 80$ tumor necrosis factor receptor in human obesity and insulin resistance. Diabetes. 1997;46(3):451-455. doi:10.2337/ diab.46.3.451

24. Fernandez-Real JM, Gutierrez C, Ricart W, Castineira MJ, Vendrell J, Richart C. Plasma levels of the soluble fraction of tumor necrosis factor receptors 1 and 2 are independent determinants of plasma cholesterol and LDL-cholesterol concentrations in healthy subjects. Atherosclerosis. 1999;146(2):321-327. doi:10.1016/S0021-9150(99) 00156-2

25. Tanaka S, Isoda F, Ishihara Y, Kimura M, Yamakawa T. $\mathrm{T}$ lymphopaenia in relation to body mass index and TNF-alpha in human obesity: adequate weight reduction can be corrective. Clin Endocrinol. 2001;54(3):347-354.

26. Aprahamian TR, Sam F. Adiponectin in cardiovascular inflammation and obesity. Int J Inflam. 2011;2011:376909. doi:10.4061/2011/ 376909

\section{Publish your work in this journal}

Biologics: Targets and Therapy is an international, peer-reviewed journal focusing on the patho-physiological rationale for and clinical application of Biologic agents in the management of autoimmune diseases, cancers or other pathologies where a molecular target can be identified. This journal is indexed on PubMed Central, CAS, EMBase,
Scopus and the Elsevier Bibliographic databases. The manuscript management system is completely online and includes a very quick and fair peer-review system, which is all easy to use. Visit http://www.dovepress.com/testimonials.php to read real quotes from published authors. 